\title{
Experimental characterization and numerical modelling analyses of nano-adhesive-bonded joints
}

\author{
Fayssal Hadjez, Brahim Necib \\ Laboratory of Mechanics, Mechanical Engineering, University of the Frères Mentouri de Constantine. Campus Chaab Ersas 25000, \\ Constantine, Algeria \\ badjez103@gmail.com
}

\begin{abstract}
Experimental and numerical characterizations of nano-adhesivebonded joints typically used in aerospace applications are presented. First, samples of single-lap joints produced using a composite reinforced with carbon fibre fabric ( $2 \%$ graphene by weight), were analysed. Five samples were produced by injecting nanostructure particles in the epoxy resin and five are not (non-reinforced resin). Shear tests were performed to measure the resistances of the bonded joints, to assess the structural performances of the structures with and without the resin. Second, finite-element numerical models were applied based on experiments on adhesive joints; in particular a numerical simulation of the adhesive lap-joint model was performed using ANSYS software. Analyses were performed for the joints with unfilled and nanofilled adhesive, focusing on the cooling process during which adhesive single-lap joints are mainly generated. The experimental and numerical model results generally agree quite well. Graphene increased the stiffness of each lap joint under a rational load charge. The nanostructure adhesive increased the failure load, but this increase depended on various parameters, including adhesive structural features and the structures of the nanostructures produced. The reinforced adhesive nanostructure was found to decrease the weight.
\end{abstract}

KEYWORDS. Adhesive; lap joints; deformation; load; adhesive bonded; nanostructures.

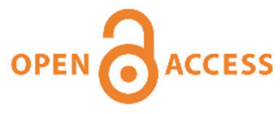

Citation: Hadjez, F., Necib, B., Experimental characterization and numerical modelling analyses of nano-adhesive-bonded joints, Frattura ed Integrità Strutturale, 44 (2018) 94105.

Received: 22.12 .2017

Accepted: 12.02 .2018

Published: 01.04 .2018

Copyright: (C) 2018 This is an open access article under the terms of the CC-BY 4.0, which permits unrestricted use, distribution, and reproduction in any medium, provided the original author and source are credited.

\section{INTRODUCTION}

\footnotetext{
A dhesive-bonded assemblies are increasingly being used in vehicles (e.g., road vehicles and aeroplanes) because an adhesive-bonded assembly is light, offers good mechanical performance, and stress is repartitioned relatively uniformly throughout the bonded area $[1,2]$. Adhesive bonding has been used in the primary structure of aircraft for some time, and is still used as an alternative to riveting. Adhesives are mainly used to bond stringers to fuselage and wing skins, and to elevator, aileron, tab, and spoiler skins. Large structures in which composites are adhesive-bonded to
} 
metals include the fuselage of the Boeing 787 passenger aircraft [3]. Premature failure of a joint can result from traditional joining methods, such as riveting or bolting, because holes are introduced to the structure. Using bonding instead of traditional joining methods avoids such problems because stress distribution is better in a bonded than in a traditional joint [4]. Nano-adhesive joints have been developed for use in the aerospace industry, and are important in many engineered components, although different nano-adhesives are used for different purposes $[2,5,6]$. Many studies of bonded lap joints for aerospace applications have been performed to improve our understanding of the mechanical properties of the joints $[8,9,10,11]$. Attempts have been made to use nano-technology to increase the stiffness of lap joints under rational load charges, to improve mechanical performance. The knowledge gained, combined with our understanding of adhesive joints reinforced with conventional additives, has given nanostructure-reinforced adhesives a key role in the aerospace and aircraft industries. The bonding potentials of adhesives can be fully exploited only if close attention is paid to interface contact, the adhesion mechanism, surface preparation, the application, the environment, and the non-destructive control modes.

The aim of this study was to evaluate the behaviours of lap-joints by performing lap-shear rupture tests on specimens of single-joint junctions reinforced with nanostructure adhesives. Robust joint designs for use in engineered structures require stress under a certain load to be known and the potential for failure to be predicted. In this study, adhesive-bonded joints were produced using an epoxy resin and a curing agent, using a composite reinforced with carbon fibre fabric as the adherent, with $2 \%$ graphene by weight added.

\section{DESCRIPTION OF THE EXPERIMENTAL WORK}

A composite reinforced with carbon fibre fabric used in the aeronautical and aerospace industries was used as the adherend in view of its attractive mechanical and physical properties. DOW D.E.R. 331 was used in the bending experiments. The curing agent, isophorondiamine, at a concentration of $22.5 \%$ by weight, was supplied by SigmaAldrich (St Louis, MO, USA). Acetone was used as supplied. When the resin nanosilicate (D.E.R. 331) was used, expanded graphene was added at $2 \%$ of the adhesive weight.

The nanostructure adhesive was prepared as follows. Acetone was added to graphene (2\% of the weight of adhesive to be used), and the mixture was placed in an ultrasonic bath and stirred for 10 min. A specified amount of the epoxy resin was added to the graphene/acetone mixture, then the mixture was ultrasonicated at $20 \mathrm{kHz}$ for 60 min. The mixture was then heated to $70{ }^{\circ} \mathrm{C}$ and stirred for $10 \mathrm{~min}$ until the mass of the epoxy resin and nanostructures produced remained constant (i.e., all of the acetone had evaporated).

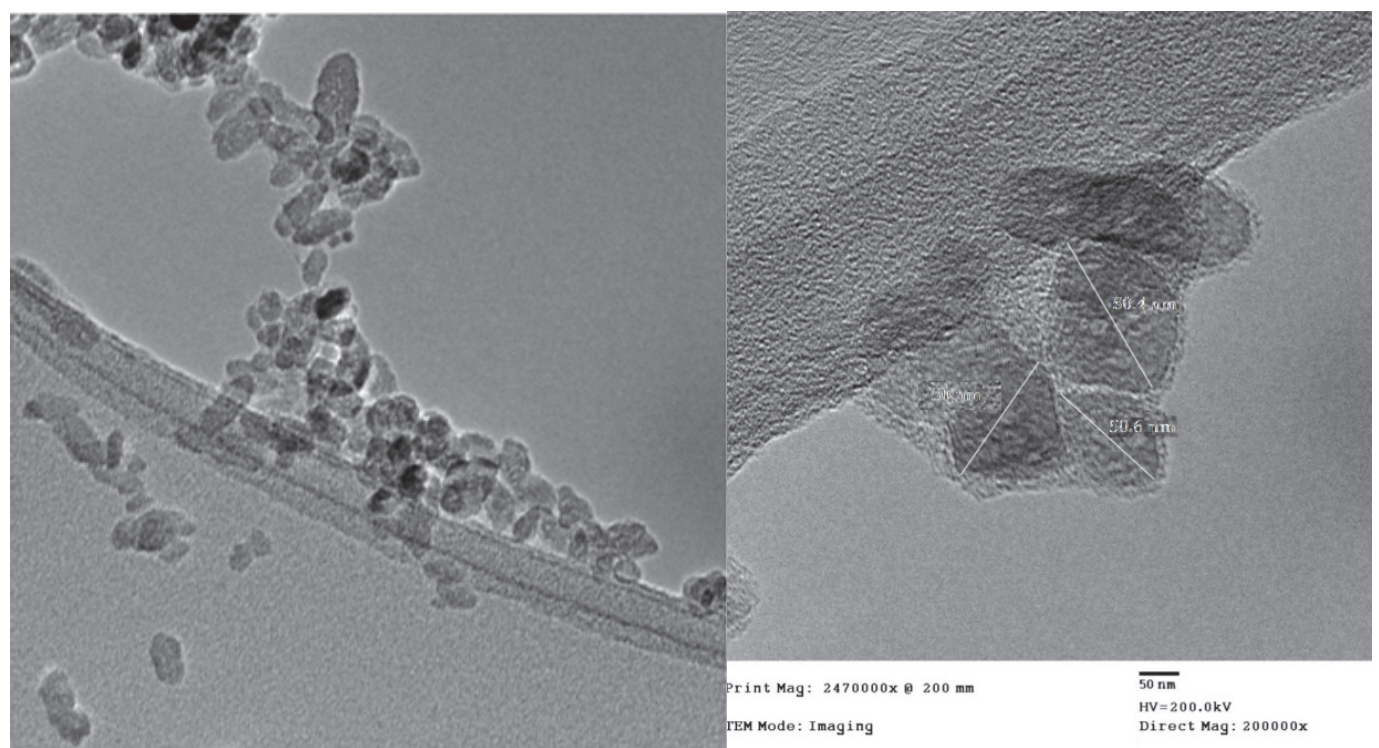

Figure 1: Microscopy images of the nanocrystalline surface of the nano-adhesive (each image is $50 \mu \mathrm{m}$ across).

Tests were performed using 32-layers of carbon fibre fabric, as the adherends. Each specimen was 76 mm thick and 101.6 $\mathrm{mm}$ long, and had a $25.4 \mathrm{~mm}$ overlap zone and a surface area of $645 \mathrm{~mm}^{2}$. Microscopy images of the adherend surfaces are shown in Fig. 1 and a photograph and schematic of a test specimen are shown in Fig. 2. The software used to acquire the 
data was used to set various output and input values to generate a series of files to best characterize the mechanical properties of the test specimen.

A machine was selected to ensure that each specimen was ruptured for an average maximum shear stress of $40 \mathrm{MPa}$ [12]. This value is typical of most aeronautical structural bonds formed using vacuum bags and autoclave cycles. The contact surface was $645 \mathrm{~mm}^{2}$, implying a load of about $26 \mathrm{kN}$, and an INSTRON Series 59804 machine was therefore selected [13]. The machine had a floor and a $50 \mathrm{kN}$ load cell. Pneumatic jaws clamped the specimen with a force of $5 \mathrm{kN}$ using flat grips, as is typical when testing the mechanical properties of composite and elastomeric materials. A test specimen in position for testing in the machine is shown in Fig. 3.

The failure load, standard deviation, and displacement curve were determined for each joint sample (five unfilled epoxy samples and five nanofilled epoxy samples). Each joint sample was broken by applying a tensile load to allow the effect of the nanostructure adhesive to be investigated.
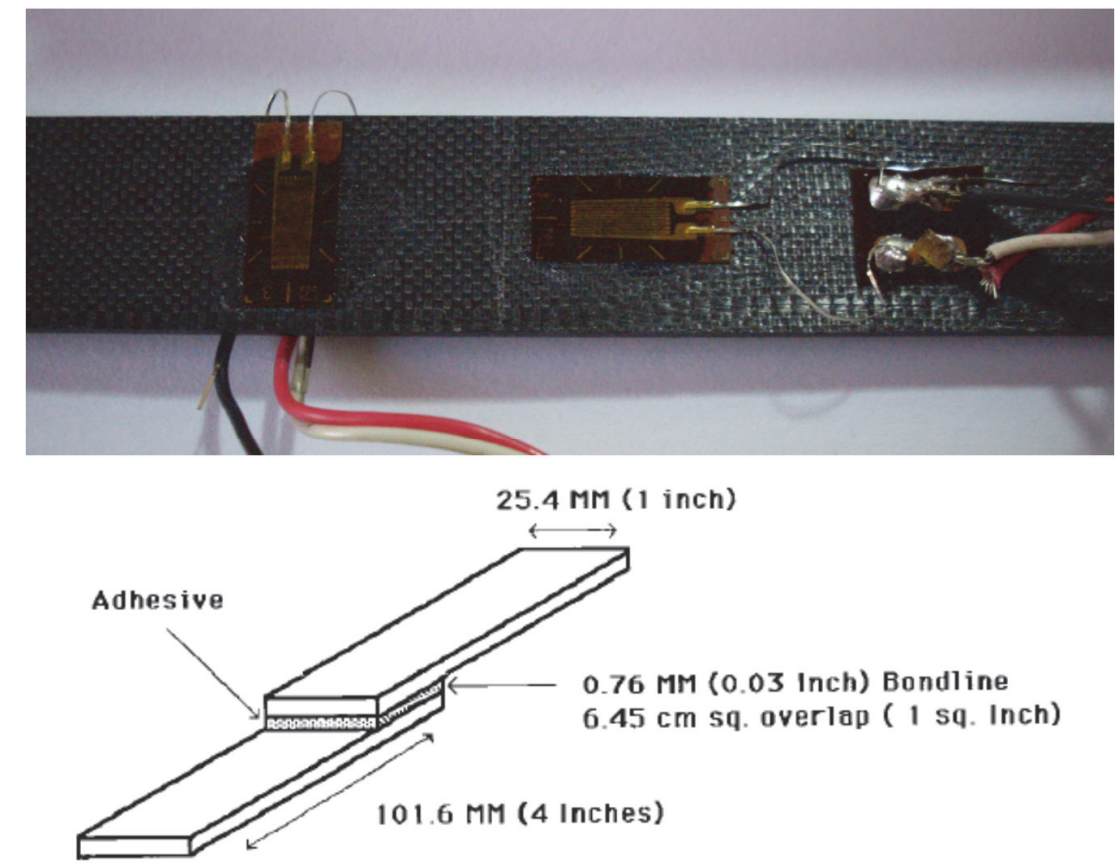

Figure 2: Photograph and schematic of a sample.

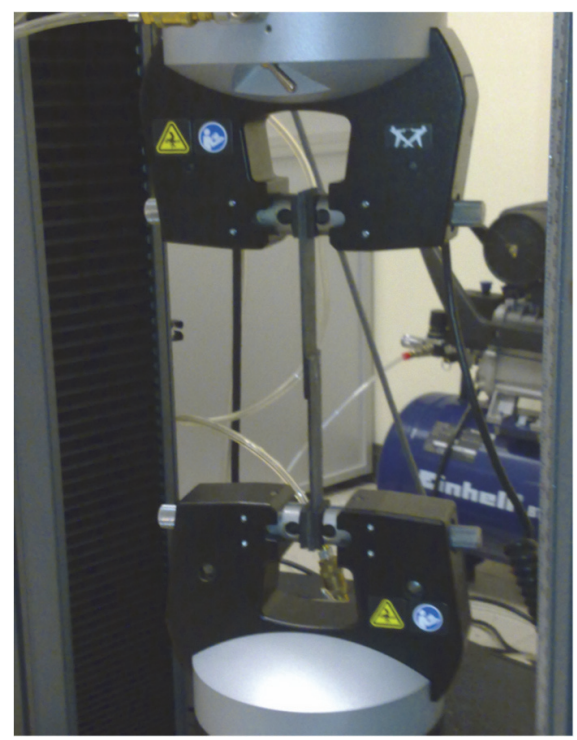

Figure 3: Photograph of a single-lap-joint specimen installed in the INSTRON testing machine in preparation for a tensile test. 


\section{EXPERIMENTAL RESULTS}

$\mathrm{F}$

ive samples injected with nanostructures were tested together with five non-injected samples, and the force displacement, maximum failure load, adhesive layer thickness, and failure mode were determined for each sample. The data were converted into .txt files and processed using MATLAB software. Each test was performed using a slide speed of $2 \mathrm{~mm} / \mathrm{min}$ and a sampling frequency of $10 \mathrm{~Hz}$.

Load graphs for the samples with lap joints formed using nanofilled adhesive and the samples with unfilled adhesive are shown in Fig. 4. The data were acquired using shear tests, and the statistical significance of the difference between the results for the unfilled and nanofilled adhesive samples was determined. The statistical significances of the difference between the maximum amounts of energy absorbed before failure and the difference between the shear strengths were determined. In our calculations, $\mathrm{F}_{\max }$ was the maximum load, $\delta \mathrm{F}_{\max }$ the displacement at maximum load, $\tau_{\max }$ the average shear strength at maximum load, and $\mathrm{E} \tau_{\max }$ the total energy defined as the area under the load/displacement curve. The results were calculated excluding data most different from the average values to allow the average properties to be evaluated without being affected by outliers caused by abnormalities not found in most of the samples.

The results indicate that the nanostructure epoxy resin performs better than the epoxy resin in terms of both mechanical strength and adhesive stiffness (energy and maximum displacement). Cracking gradually occurred during the tests, as determined from the cracking sounds emitted. A sharp sound indicated the snapping of each sample.

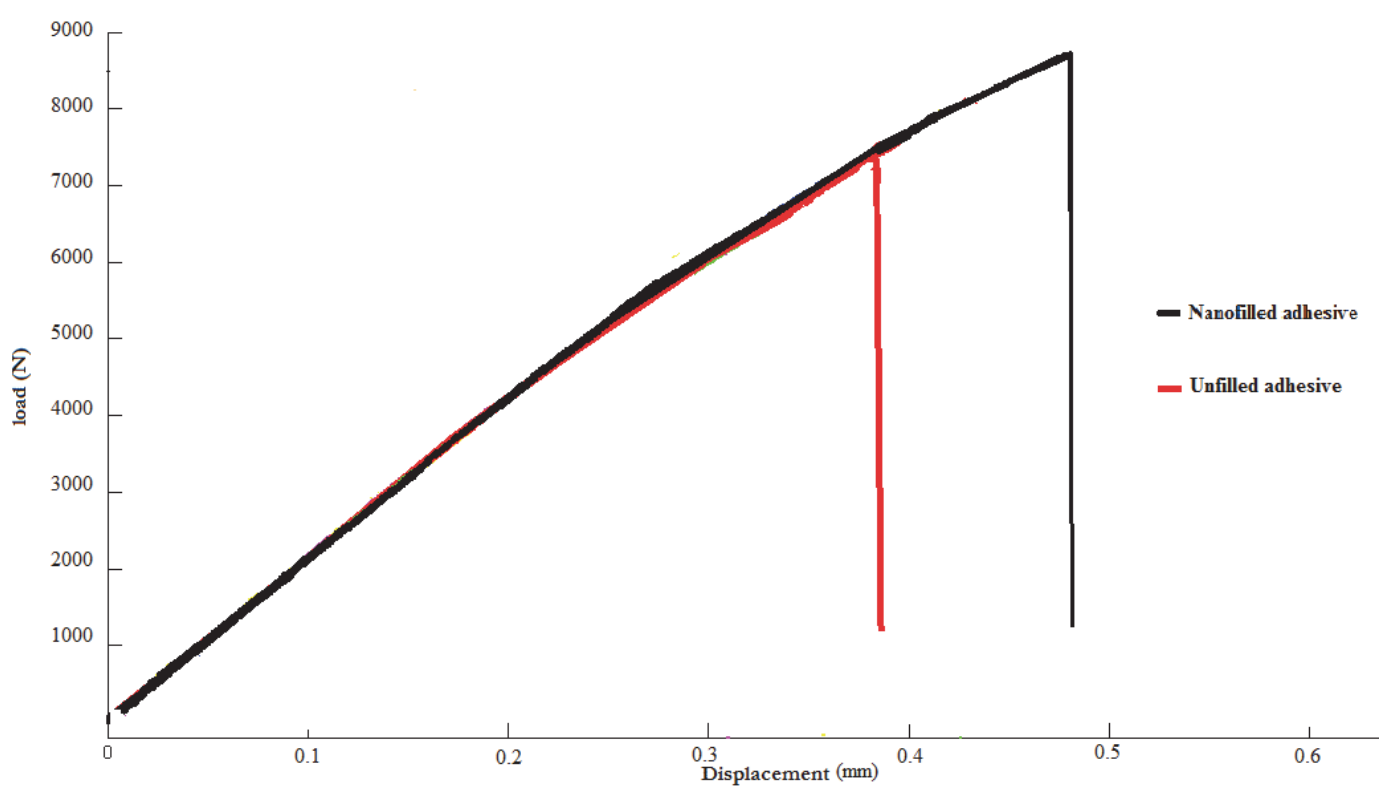

Figure 4: Displacement/load plots for the unfilled and nanofilled epoxy resin samples

\begin{tabular}{lll}
\hline & Unfilled Epoxy & Nanofilled Epoxy \\
$F_{\text {max }}(N)$ & 7130.8 & 8345.9 \\
$\partial_{F}(\mathrm{~N})$ & 671.1 & 245.9 \\
\hline$\delta_{F \max }(\mathrm{mm})$ & 0.3670 & 0.439 \\
$\delta_{F \max , a v}$ & 1.040 & 0.0270 \\
\hline$\tau_{\max }(M P a)$ & 11.02 & 12.99 \\
$\partial \tau_{\max }(M P a) \tau$ & 1.040 & 0.39 \\
\hline$E_{\text {tot }}^{\max }(\mathrm{mJ})$ & 1699.7 & 1989 \\
$\partial_{E}(\mathrm{~mJ})$ & 332.4 & 199.46 \\
\hline
\end{tabular}

Table 1: Mean values and standard deviations of the main force-deformation parameters for the samples that were tested.

The force and displacement curves for the joints formed using unfilled and nanofilled adhesive shown in Fig. 4 indicate that adding nanostructures to the rigid adhesive increases the displacement capacity of the joint. This indicates that the addition of nanostructures increases the absorption of failure formations within the joint, and significantly increases the failure load 
of the joint. However, adding $2 \%$ graphene to the adhesive without adding nanostructures decreased the force-displacement capacity of the joint.

It can be seen from Tab. 1 that the standard deviations of the force-deformation parameters were lower for the single-lap joints formed using nanofilled adhesive than for the single-lap joints formed using unfilledadhesive. This indicates that the nanofilled adhesive formed reliable and reproducible joints.

\section{NUMERICAL SIMULATIONS}

$\mathrm{N}$ umerical simulations were performed using ANSYS WORKBENCH software, which is an integrated platform containing application packages that can interact with each other, the database generated in one block (see Fig. 5) being transferrable to another. The software has a versatile graphical interface.

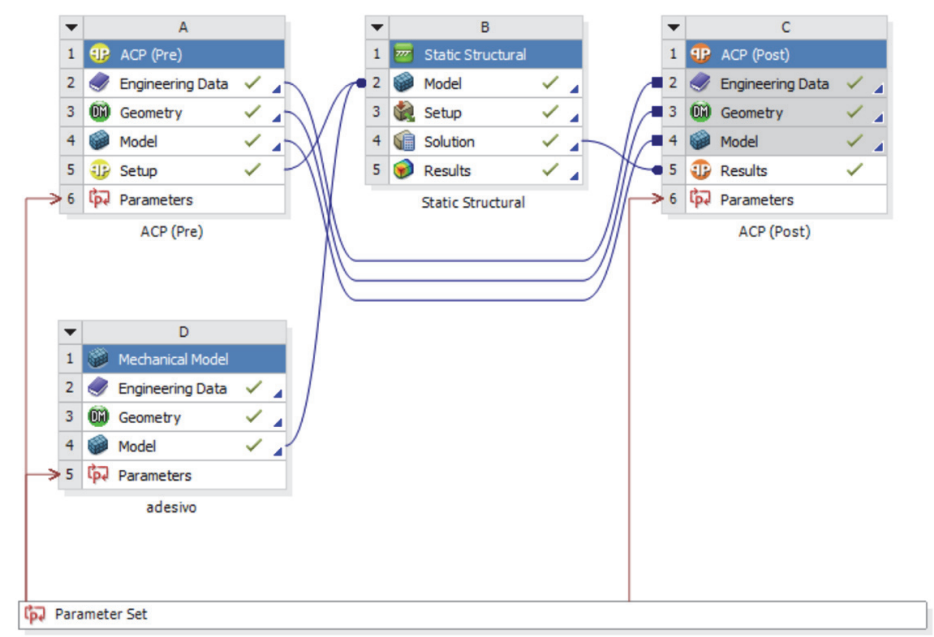

Figure 5: Block structure of the ANSYS WORKBENCH software.

It has been observed in various studies that altering the resin module of a bond also affects the overall stiffness of the joint. It was not possible to set the stiffness of the adhesive film affecting deformation at the point at which the bonded joint broke using only cohesive zone modelling (CZM) parameters. However, the $\tau$ max and ERRTcrit (critical total energy release rate) values controlled the breaking load. Performing several iterations gave the values shown in Tab. 2 . These values were related to the mesh configurations and the total numbers of steps. The force-displacement features shown in Fig. 5 were obtained from these parameters. The main parameters are shown in Tab. 3, and the errors with respect to the experimental values shown in Tab. 1 are also shown. The uncertainties were acceptable from an engineering point of view for almost all the values, but the energy error was an order of magnitude higher than the errors in the other parameters. This was caused by the accumulated uncertainties in the various parameters (such as rigidity, displacement, and force) used to evaluate the energy.

\begin{tabular}{ccc}
\hline & $\tau_{\max }(\mathrm{MPa})$ & $\operatorname{Err}^{\mathrm{c}}$ crit $\left(\mathrm{mJ} / \mathrm{mm}^{2}\right)$ \\
Unfilled Epoxy & 15.78 & 0.093 \\
Nanofilled Epoxy & 18.34 & 0.09 \\
\hline
\end{tabular}

Table 2: Cohesive zone model parameters.

The coefficient Kt (contact stiffness), reflecting the specific rigidity of the contact area in the "reversible" section, was $340.16 \mathrm{GPa} / \mathrm{mm}$. Decreasing the Young modulus of the unfilled adhesive film from 2400 to $240 \mathrm{MPa}$ resulted in $\mathrm{Kt}=$ $34.64 \mathrm{GPa} / \mathrm{mm}$, which was about an order of magnitude less than $\mathrm{Kt}$ for the "reversible" section. Therefore, as shown in the force-displacement curves in Fig. 6, a more rigid film causes the material to be stiff, fragile, and less resistant, causing accelerated damage in the cohesive elements. 


\begin{tabular}{|c|c|c|}
\hline & Unfilled Epoxy & Nanofilled Epoxy \\
\hline $\begin{array}{l}F_{\max } \\
\text { Error }\end{array}$ & $\begin{array}{l}7456.8 \\
0.24 \% \\
\end{array}$ & $\begin{array}{l}8983.9 \\
0.05 \%\end{array}$ \\
\hline $\begin{array}{l}\delta_{\text {Fmax }} \\
\text { Error }\end{array}$ & $\begin{array}{l}0.345 \\
3 \% \\
\end{array}$ & $\begin{array}{l}0.439 \\
2.62 \%\end{array}$ \\
\hline $\begin{array}{l}\tau_{\text {max }, a v} \quad(M P a) \\
\text { Error }\end{array}$ & $\begin{array}{l}11.12 \\
0.63 \% \\
\end{array}$ & $\begin{array}{l}13.09 \\
0.18 \% \\
\end{array}$ \\
\hline $\begin{array}{l}E_{\max } \quad(m J) \\
\text { Error }\end{array}$ & $\begin{array}{l}1699.7 \\
16.03 \%\end{array}$ & $\begin{array}{l}2245.3 \\
13.19 \%\end{array}$ \\
\hline
\end{tabular}

Table 3: Main results of the simulations, and the errors with respect to the experimental results.

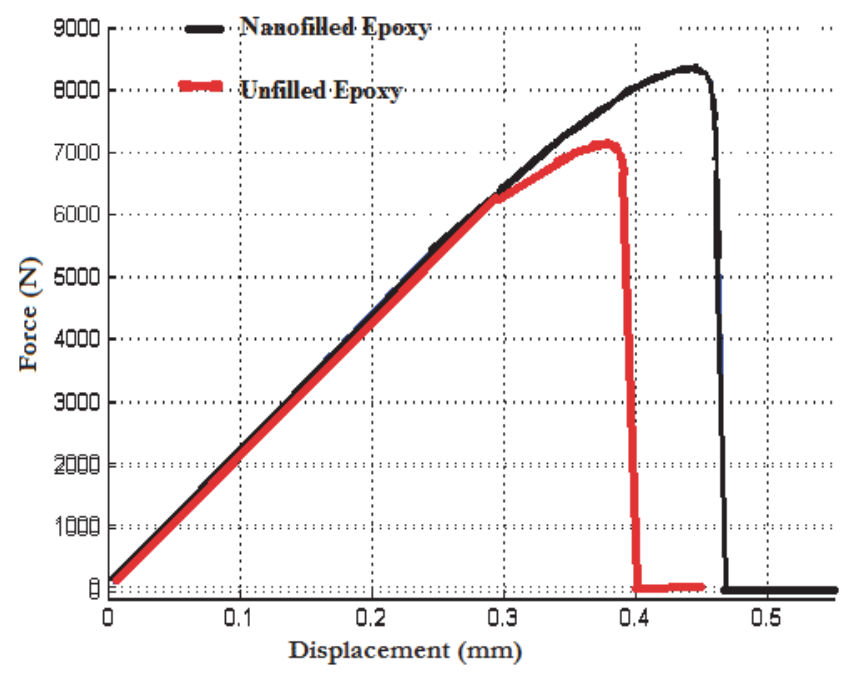

Figure 6: Force-displacement curves for the samples formed using unfilled and nanofilled adhesive.

\section{Discussion}

he adhesive stresses obtained using the software model based on finite element analysis are now compared with the experimental results. The stress distributions were modelled for a single adhesive lap joint, as shown in Fig. 9a and 9b. The force-displacement curves shown in Fig. 10a and 10b indicate that the failure loads of the joints increased because the displacement capacity of the nanostructure joint type increased. The increase in joints containing nanostructures supports our conclusion from the experimental results that adding nanostructures increases the average failure load.

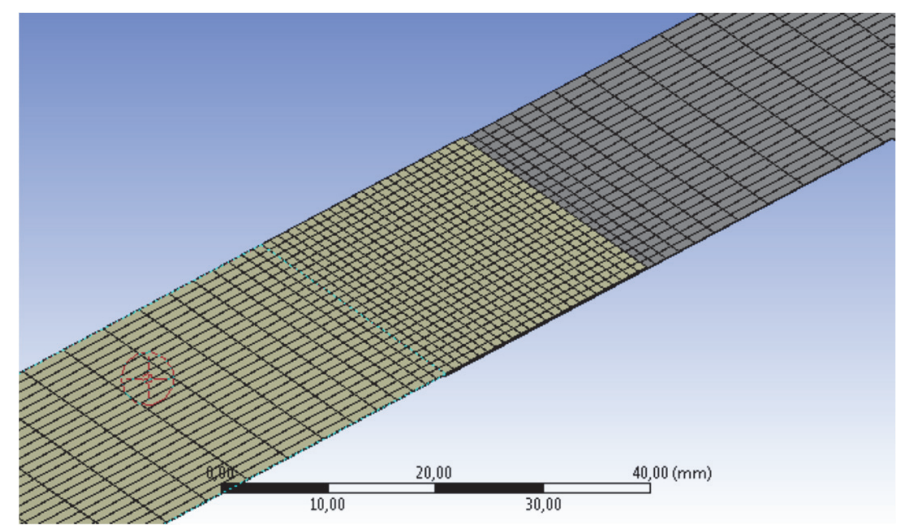

Figure 7: Finite element model. 


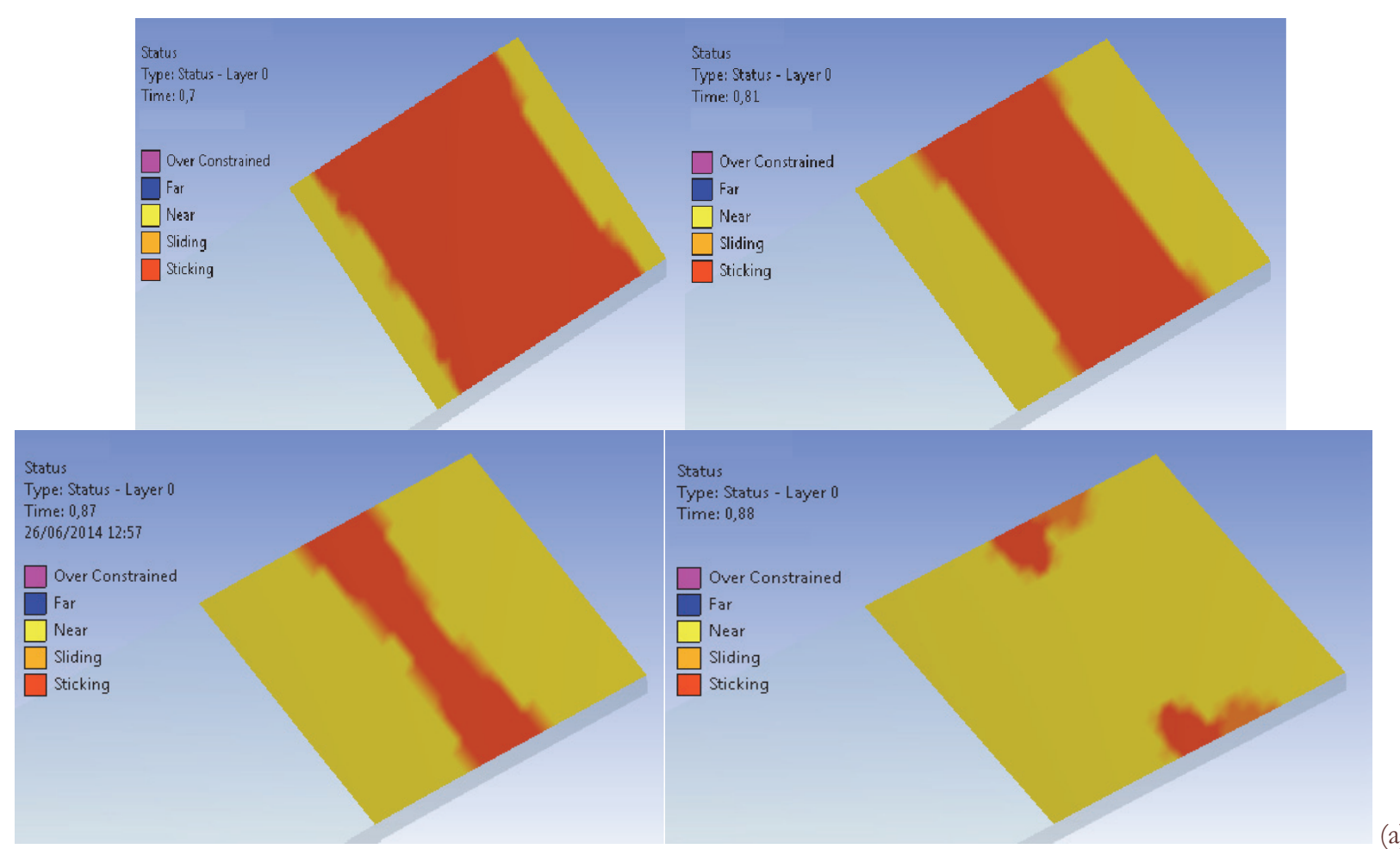

(a)
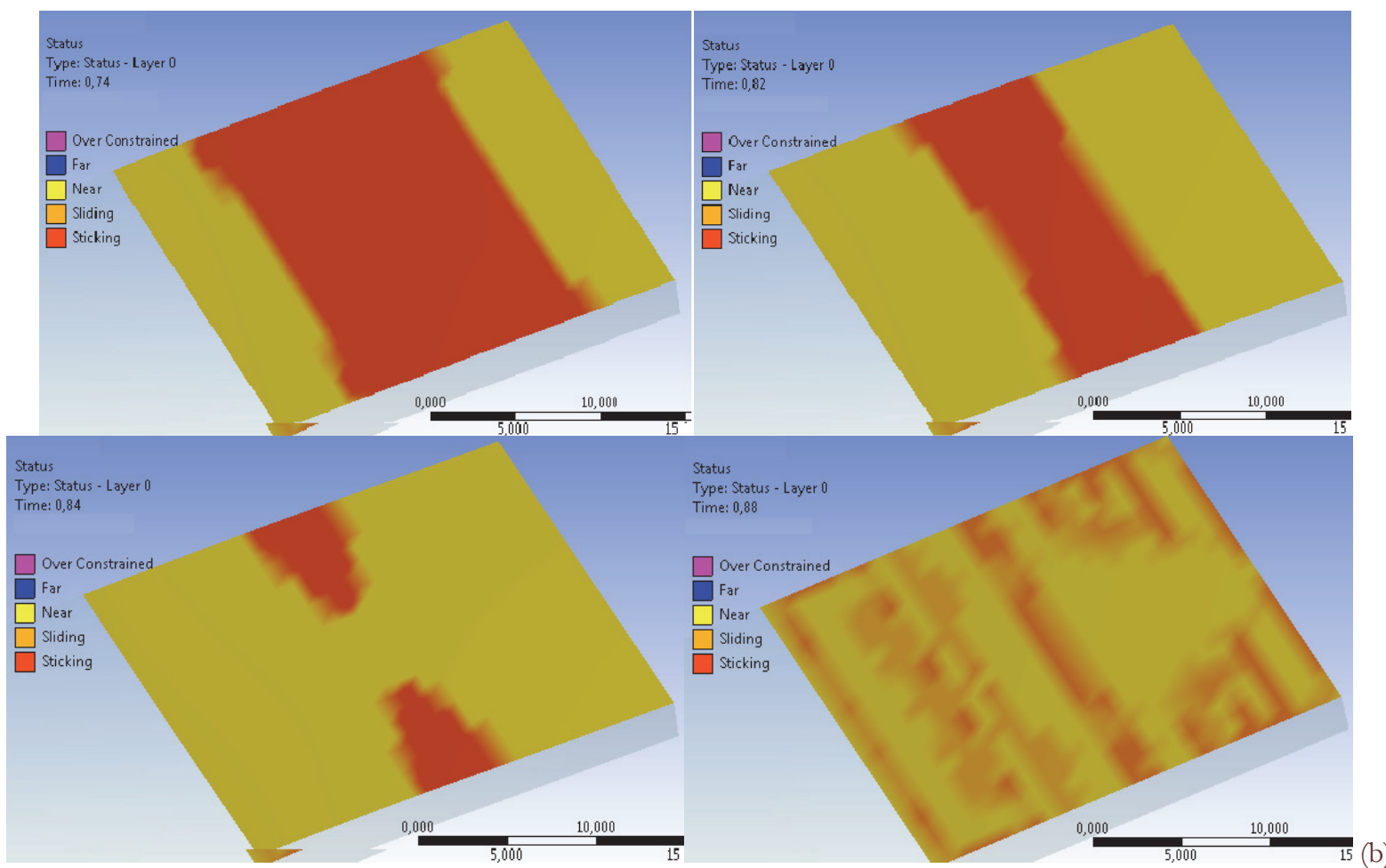

Figure 8: Contact states for (a) the unfilled epoxy resin samples and (b) the nanofilled epoxy resin samples

The numerical analysis indicates that stress in an adhesive-bonded single-lap joint occurs at the edge of the overlap region. Decreasing this stress considerably increases the load-carrying and displacement capacities. Different joint geometries and adhesive additives have been used to decrease peel stress. The displacement capacity was higher for the nanofilled than for the unfilled adhesive, as shown in the force-displacement curves in Fig. 9c and 9d. However, too big an increase in the 
displacement capacity negatively affects the failure load of the joint, as also shown by the curves. Increasing the extent of nanofilled reinforcement increases the flexibility of the adhesive, which in turn increases the displacement capacity of the joint and decreases the failure load (see Fig. 9c and 9d).

The advancement of a crack can be studied from the trend in tangential stress along the centreline of the CZM contact, using the overlap and load as parameters. It can be seen from Fig. 9a and 9b that increasing the load decreases the overlapping zone, decoupling the contact. Specifically for the nanofilled adhesive, the transition from purple to red in the curve for the transition from the tension state indicates the beginning of structural disintegration of the joint and thus the beginning of the crack path (characterized by the loss of tangential tension to the extreme ends of the overlapping area). This failure involves a decrease in the rigidity of the joint, reflected in the change in the force-displacement curve shown in Fig. 6. The plot shown in Fig. 6 stops being linear at the corresponding loading value.

The $\mathrm{T}$ diagrams in Fig. 9a and $9 \mathrm{~b}$ indicate some similarities between the curves for the first two (lower) loads, helping us to validate the numerical contact model. The $\tau(\delta)$ curves were obtained using the ANSYS parametric design language macro. In this macro, the contact and target surfaces selected to create the CONTA174 element were used in the numerical model to represent contact and the relationship between the 3-D target surface and the deformable surface. These plots confirmed the trend in the bilinear numerical model and allowed simulations to be validated by verifying (using the same macro) the $\mathrm{ERR}^{\mathrm{T}}$ crit values and comparing the values with those used in the cohesive model. The results are shown in Tab. 4 . The errors shown in the table are computational and discretization errors.

\begin{tabular}{ccc}
\hline & $E$ & Error \\
Unfit & $\left(\mathrm{mJ} / \mathrm{mm}^{2}\right)$ & $3.6 \%$ \\
Nanofilled Epoxy & $8.643 \times 10^{-2}$ & \\
& $9.713 \times 10^{-2}$ & $7.9 \%$ \\
\hline
\end{tabular}

Table 4: ERR ${ }^{\mathrm{t}}$ values.

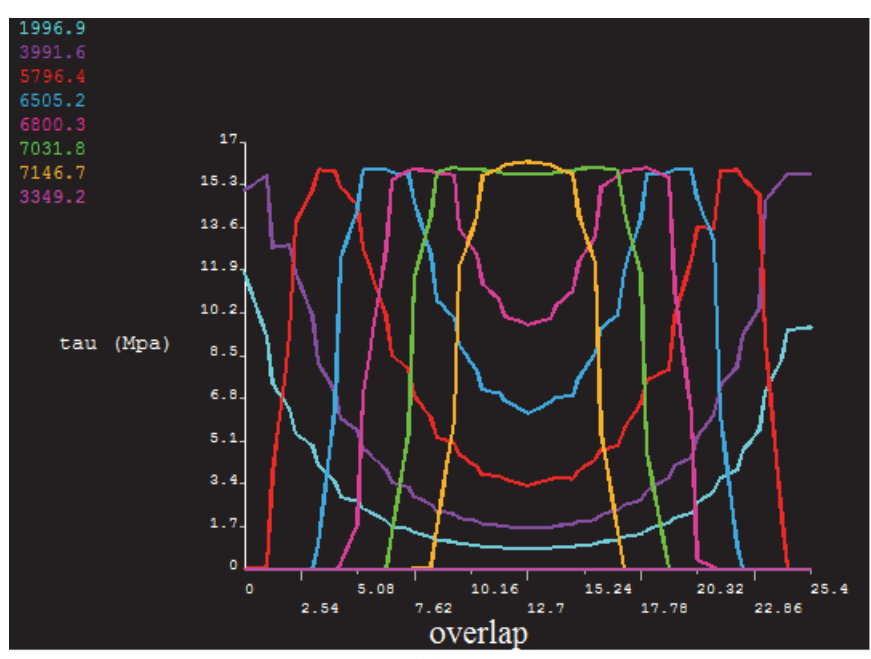

(a)

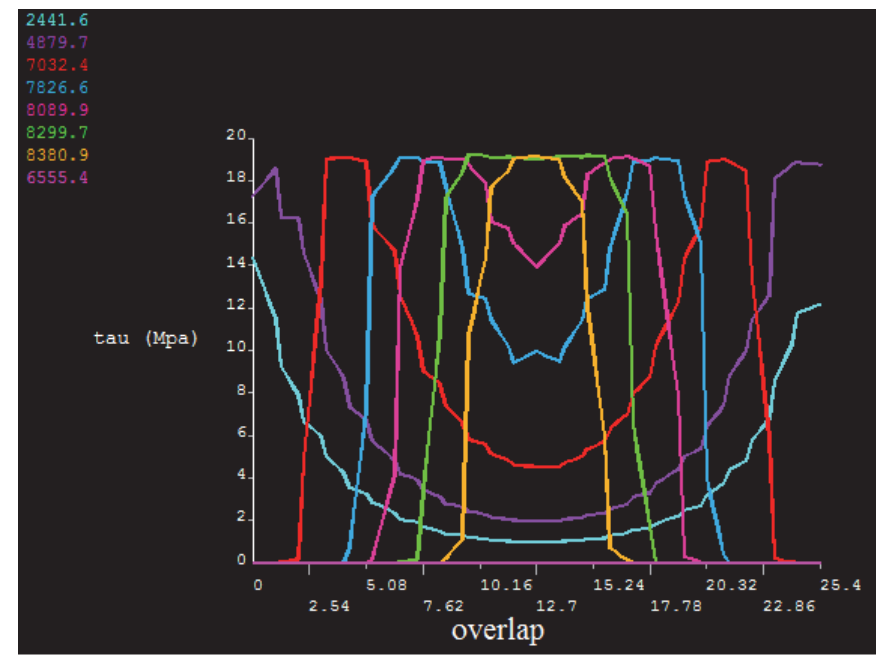

(b)

Figure 9: Tangential tension in the middle of the cohesive zone modelling contact at various loads (in N) for (a) the unfilled epoxy resin samples and (b) the nanofilled epoxy resin samples.

The breaking load of a joint is greatly affected by increasing the breaking load of the joint or decreasing the amount of nanostructures added. The face did not advance in a straight line along the junction width but was found to have a slight bend. This is because the deformable lower joints in the central zone were linked to the higher triaxial state of the tension state, causing more delicate contact behaviour or the breaking conditions of the CZM elements to advance. The crack propagation velocity increased as the crack advanced towards the central cohesive zone. This is because the tension increased due to the increased load and decreased surface resistance. However, for the ANSYS WORKBENCH crest forehead evaluation, a defined output parameter was used as part of the Contact Tool with the aim of filling the state of the CZM 
contact. The contact state at the same voltage step and adhesion-adhesive interface as shown in Fig. 8a and 8b is shown in Fig. $9 \mathrm{a}$ and $9 \mathrm{~b}$.
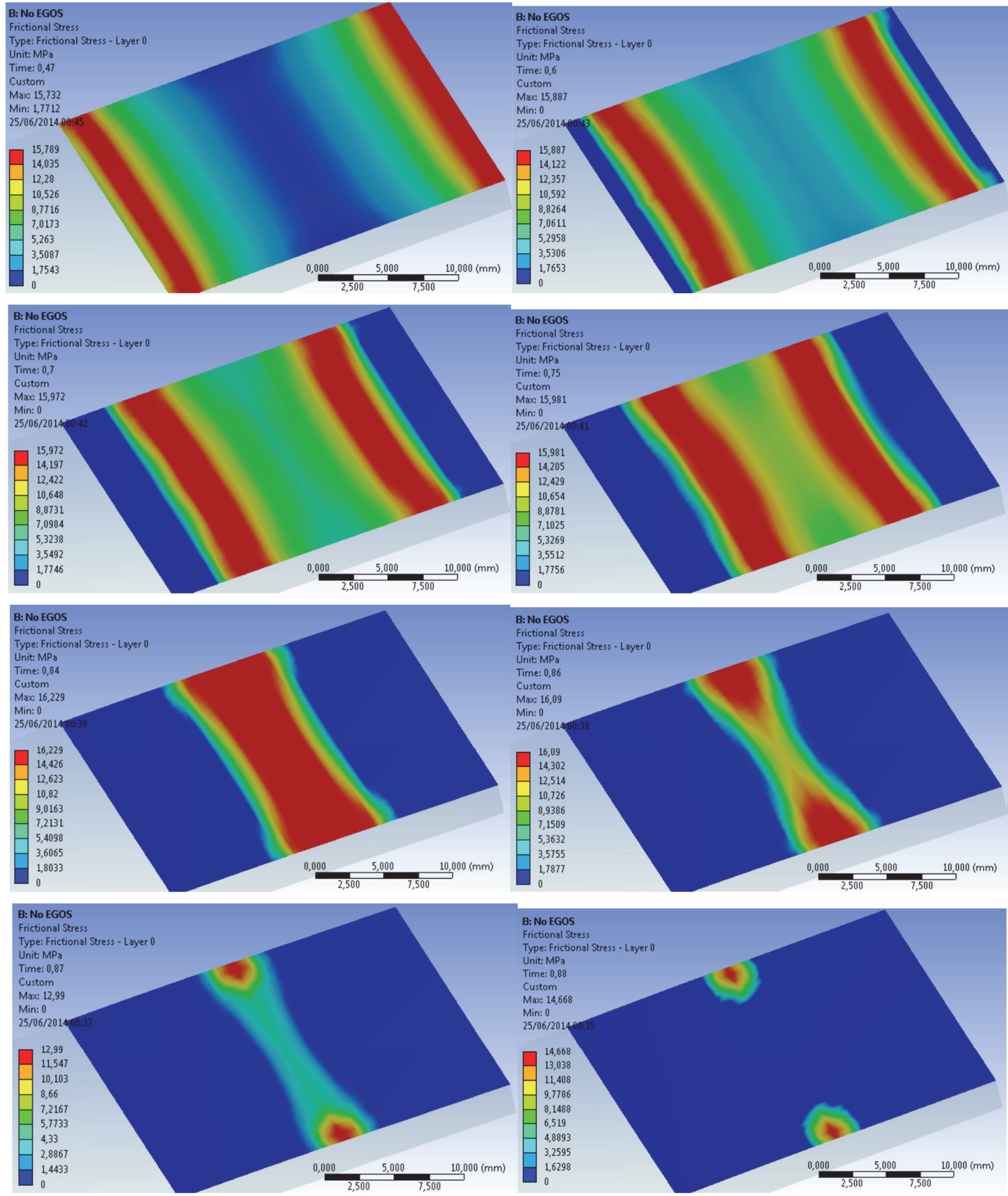

(c)

Figure 9: Shear stress at the interface in the unfilled epoxy resin samples (c). 

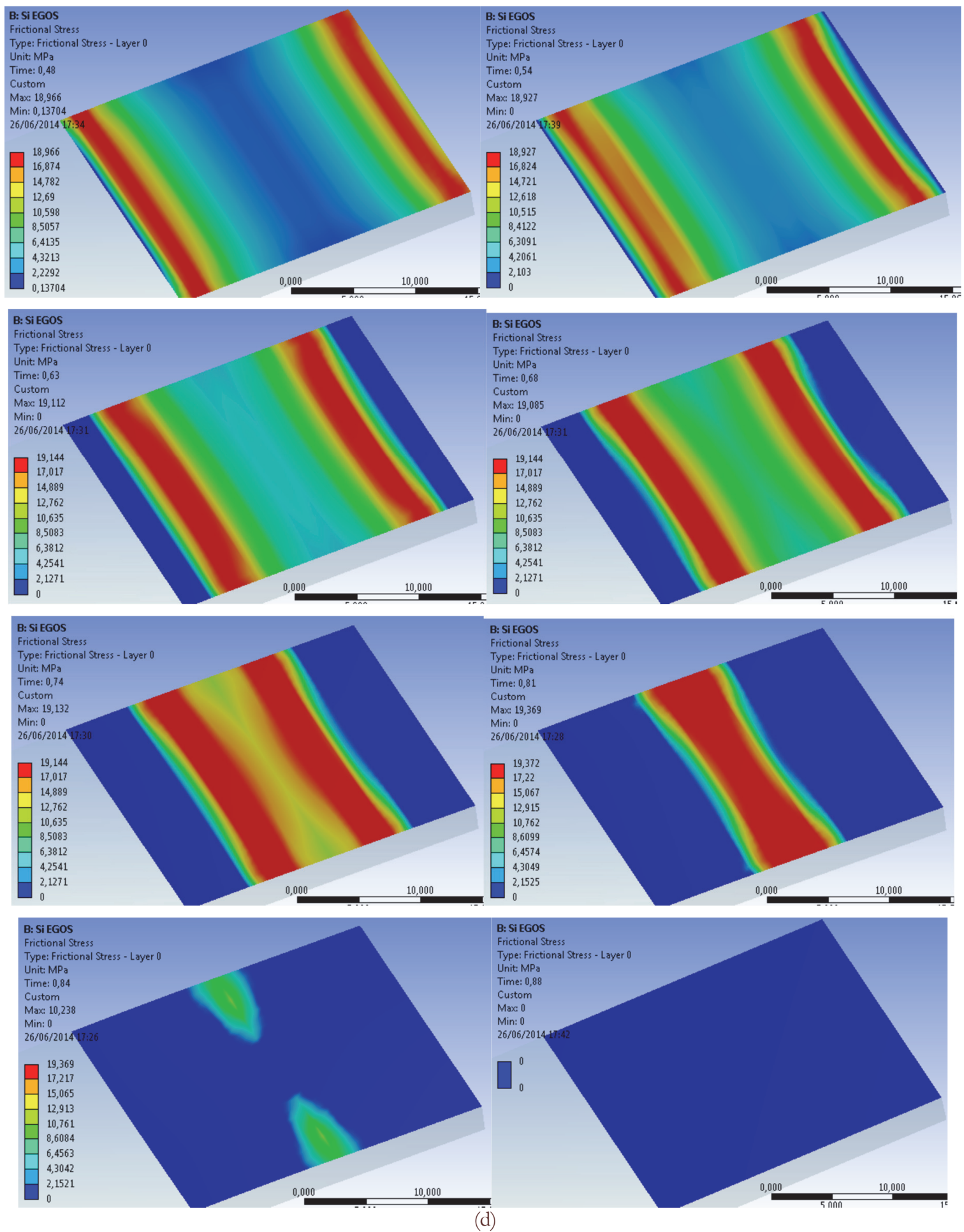

Figure 9: Shear stress at the interface in the nanofilled epoxy resin samples (d).

Failure started at the edges of the lap regions and propagated to the centres of the adhesive-bonded single-lap joints. The force-displacement curves indicate that too rigid a film anticipates and accelerates damage to the cohesive elements because of the rigid behaviour making the material more fragile and less resilient. The experimental and simulation results are compared in Fig. 10a and 10b. The comparison allows the numerical model to be quantitatively validated, revealing a good fit with the experimental data. 

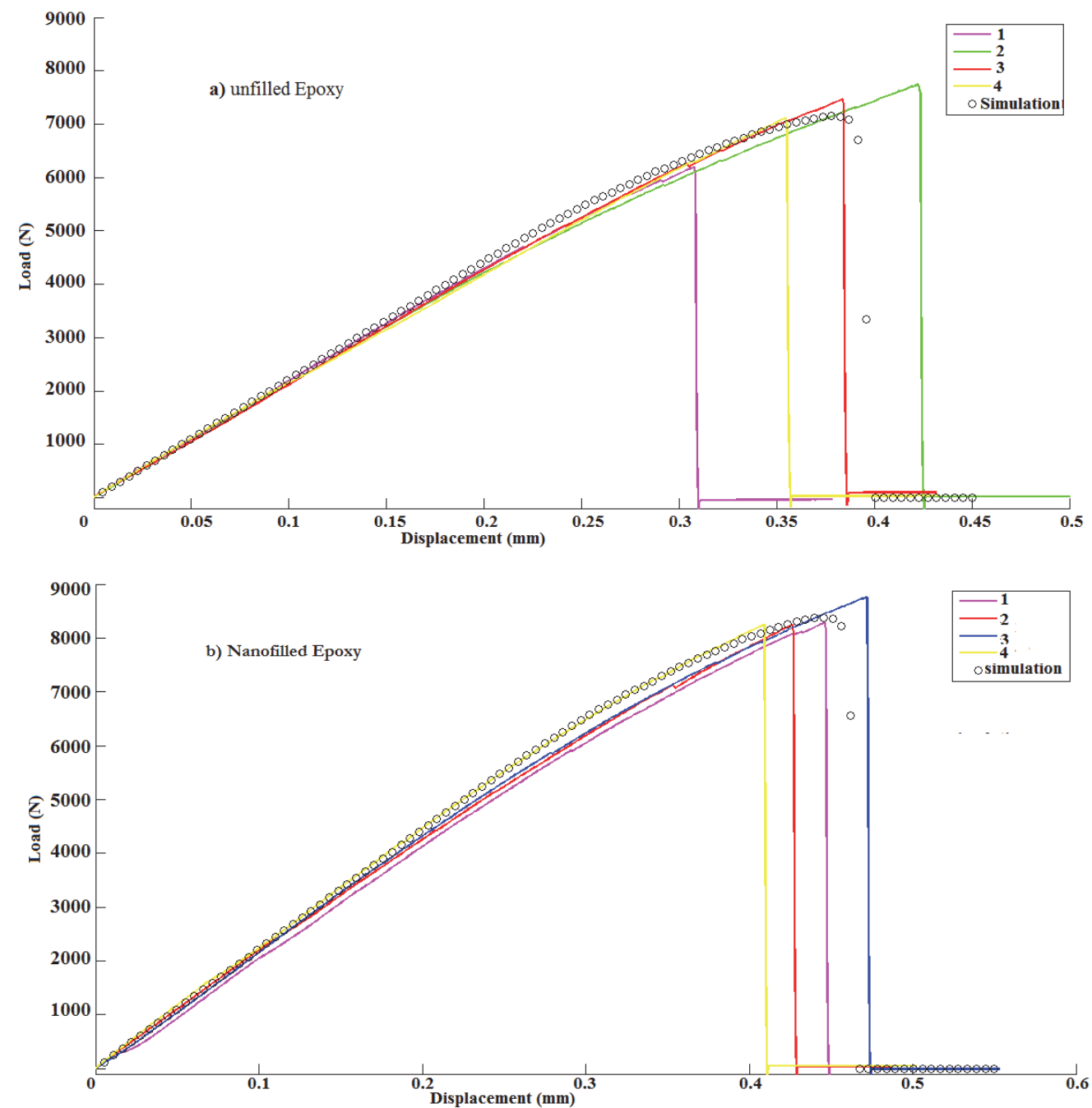

Figure 10: Comparison of the experimental and numerical data for the single-lap joints (a) without and (b) with nanofilled epoxy resin.

\section{CONCLUSIONS}

7 he effect of adding a flexible reinforced nanostructure adhesive (produced by adding $2 \%$ graphene by weight) on tensile failure load in a single-lap joint was investigated numerically and experimentally. The main aims of adding the graphene were to:

improve mechanical performance;

- distribute the stresses along the bonded area in a relatively uniform manner;

- decrease the weight of the structure (e.g., for use in aerospace applications).

Adding homogeneous epoxy resin containing graphene nanostructures increased the maximum load by $17.6 \%$ and the total energy under the curve by $40.7 \%$. The graphene allowed more energy to be absorbed because the lamellae could slide against each other. However, the various functional groups in the EG allowed the load to be transferred to the extremely rigid and resistant parts. The FEM model indicated that any glued junction needs to be modelled as an adhesive film rather than as a mesh infiltrate using only CZM elements for the two adhesives. The stiffness of the joint, particularly when increased by modifying the Young's modulus of the resin forming the adhesive film, was not greatly affected by the film thickness (generally 50-500 $\mu \mathrm{m}$ ). The numerical model matched the experimental data well, and the maximum errors were reasonable. The numerical modelling method should be developed to represent a glued junction to "calibrate" a model based on doublelap shear traction tests using displacement acquisition systems. This was achieved using extensometers to assess the stretching model for specimens accurately, avoiding major deformations typical in single-lap shear tests using glued joints. The model was not that sensitive to the peeling mode even though there was adherence in the overlapping area. Using a 
double-overlapping numerical model therefore allows CZM contact behaviour to be modelled more accurately as far as shearing is concerned.

The improvements in strength, thickness, adhesive parameters, overlap length, and other factors obtained by adding graphene will allow joints to be developed with much better mechanical performances than is currently possible.

\section{REFERENCE}

[1] Emmanuel, S., Mathieu, R., Anissa, M. and Michel, C., (2015). The transmission of Lamb waves across adhesively bonded lap joints to evaluate interfacial adhesive properties. Physics procedia, 70, pp. 541-544.

[2] Stein, N., Weisgraeber, P. and Becker, W., (2015). A model for brittle failure in adhesive lap joints of arbitrary joint Configuration, Composites structures, 2015, pp. 707-718.

[3] Bo Zhao, N. and Zhen-HuaLu,Yi, N., (2011). Closed-form solutions for elastic stress-strain analysis in unbalanced adhesive single-lap joints considering adherend deformations and bond thickness, International journal of adhesion and adhesives, 31(6), pp. 434-445.

[4] Papanicolaou, G.C., Portan, D.V., Petropoulos, G.N. and Kontaxis, L.C., (2016). Effect of TiO2 Nanotubes Developed On Pure Titanium Substrates On The Mechanical Performance Of Titanium-Titanium Single-Lap Adhesive Joints, Ciência \& Tecnologia dos Materiais, 28(2), pp. 130-137.

[5] Silva, L F., Adams, R. and Gibbs, M. (2004). Manufacture of adhesive joints and bulk specimens with high-temperature adhesives, International journal of adhesion and adhesives, 24(1), pp. 69-83.

[6] Ye, Z., Vassilopoulos, P. and Thomas K., (2009). Environmental effects on fatigue behavior of adhesively-bonded pultruded structural joints, Composites sciences and technology, 69(7-8), pp. 1022-1028.

[7] Ahmed, S. and Talreja, R, (2016). A numerical study of failure of an adhesive joint influenced by a void in the adhesive. Composite Structures, 156, pp. 165-170.

[8] Zhou, H.-L.-Z., Liu, H.-Y., Zhou, H., Zhang, Y., Gao, X. and Mai, Y.-W., (2016). On adhesive properties of Nanosilica/epoxy bonded single-lap joints, materials and design, 95(5), pp. 212-218.

[9] Tomasz, S., Golewski, P. and Knec, M., (2014). Experimental investigation and numerical modelling of spot welding-adhesive joints response, Composites structures, 112, pp. 66-77.

[10] Stein, N., Felger, J. and Becker, W., (2017). Analytical models for functionally graded adhesive single lap joints: a comparative study, International journal of adhesion and adhesives, 76, pp. 70-82.

[11] Heidarpour, F., Farahani, M. and Ghabezi, P. (2018). Experimental Investigation of the Effects of Adhesive Defects on the Single Lap Joint Strength, International journal of adhesion and adhesives, 80, pp. 128-132.

[12] Zhu, Y. and Kedward, K, (2005). Methods of analysis and failure predictions for adhesively bonded joints of uniform and variable bondline thickness, Federal Aviation Administration.

[13] ASTM D 5868-95, (2002). Standard Test Method for Lap Shear Adhesion for Fiber Reinforced Plastic (FRP) Bonding, ASTM. 